THUFULI: Jurnal Pendidikan Islam Anak Usia Dini

Volume 2 Nomor 2 Tahun 2020

e-ISSN: $2685-161 \mathrm{X}$

\title{
UJI KELAYAKAN AHLI MATERI PADA PENGEMBANGAN MEDIA PERMAINAN TRADISIONAL ENGKLEK DIKONSEP GEOMETRI ANAK USIA DINI
}

\author{
Nurul Istiqomah ${ }^{1}$, Ifa Aristia Sandra E. ${ }^{2}$ \\ Pendidikan Guru Pendidikan Anak Usia Dini, Universitas PGRI Ronggolawe \\ e-mail: 1nurulistiqomah719@gmail.com, 2sandrachemistry86@gmail.com,
}

Diterima:10 November 2020 I Direvisi: 17 November 2020 I Disetujui: 19 November 2020 (C)2020 Pendidikan Guru Raudhatul Atfhal Fakultas Agama Islam Universitas Islam Malang

\begin{abstract}
This research and development aims to determine the feasibility level of the material in the traditional early childhood crank game media. The media development method used in this development was adapted from the Thiagarajan 4-D development model. Data collection techniques from the results of a questionnaire or questionnaire. The results of the validation carried out by two material experts are as follows: 1) Conformity with Basic Competence (KD) is 4 with $80 \%$ eligibility criteria. 2) Learning aspect is 3.6 with $72 \%$ eligibility criteria. 3) Material presentation is 4 with $80 \%$ eligibility. So it can be concluded that the material on the traditional crank game media "WORTH" to be presented.
\end{abstract}

Keyword: Traditional play, Engklek, Geometry

\section{A. Pendahuluan}

Anak Usia Dini menurut Augusta (2012) adalah individu yang unik dan mempunyai ragam pertumbuhan dan perkembangan dalam aspek fisik motorik, kognitif, sosial emosional, kreatifitas, bahasa dan komunikasi yang khusus sesuai usia anak. Anak usia dini menurut Mulyani (2016) merupakan individu yang mempunyai karakteristik yang berbeda sesuai tahapannya, dan memiliki sifat yang unik. Dalam memberikan pelayanan pendidikan terhadap peserta didik, pendidik harus mengetahui karakteristiknya terlebih dahulu, agar mengerti bagaimana cara mendidik baik dan benar. Hal ini dikuatkan oleh pendapat Zaporozhets (dalam Leong dan Elena, 2012) yang menyatakan bahwa,

This work is licensed under Creative Commons Attribution Non Commercial 4.0 International License Available online on: http://riset.unisma.ac.id/index.php/fai/index 
pendidikan prasekolah tidak boleh ditempuh secara akselerograf, karena tidak akan maksial hasilnya. Itulah uniknya pendidikan anak usia dini. Dari hal tersebut, dapat diambil kesimpulan bahwa anak usia dini adalah individu yang memiliki keunikan dan mempunyai karakteristik yang berbeda sesuai dengan tahap usianya.

Menurut Desy (2014) Kemampuan kognitif merupakan kemampuan yang mana anak dapat berpikir secara logis, dan cara mendapatkannya melalui informasi-informasi yang diketahui. Ide-idenya yang realistis serta menyangkut kecerdasan seseorang dalam memecahkan suatu masalah. Kognitif sangat berhubungan dengan kemampuan matematis. Menurut Sulyandari (2019), kemampuan matematika tidak melulu soal berhitung, namun pemahaman konsep sangat penting untuk menjadi perhatian tertentu. Pemahaman konsep dalam bentuk bangun ruang dan bangun datar merupakan pemaparan geometri (Ismayani, dalam Yuni: 2019). Sulyandari (2017) menyebutkan bahwa, salah satu tahap belajar matematika adalah mengenal geometri. Menurut Susanto (2011), geometri adalah cabang matematika yang berhubungan dengan bentuk, ukuran, posisi relative tokoh, dan ruang. Untuk mengenalkan bentuk geometri pada anak usia dini terdiri dari segitiga, persegi, dan lingkaran. Geometri itu sendiri merupakan bagian dari salah satu aspek perkembangan kognitif yang termasuk dalam lingkup berpikir logis. Dalam lingkup ini, ada beberapa aspek diantaranya mengenai konsep bentuk, warna, dan ukuran. (Beaty: 1996). Geometri untuk anak TK adalah mengenali bentuk, nama-nama dari benda geometri, membangun atau menyusun tanpa pola, menggambarkan geometri tanpa pola, dan bermain bangun geometri baik 2 atau 3 dimensi dengan pola yang jelas seperti rumah dan lain-lain. (NCTM, 2000). Dari beberapa pendapat ahli tersebut di atas, maka dapat disimpulkan bahwa, geometri adalah suatu konsep yang membahas mengenai bangun datar dan bangun ruang.

Menurut Azhar Arsyad (2002), media pembelajaran adalah sebuah alat yang mempunyai fungsi untuk menyajikan pesan pembelajaran. Pembelajaran anak usia dini melalui bermain. Menurut Anderson (2010), bermain dibutuhkan karena dapat menstimulus pertumbuhan anak diantaranya adalah menstimulus koneksi sel-sel syaraf. Belajar matematika untuk anak TK lebih baik menggunakan benda karena menurut Wolfinger (1994), anak-anak akan lebih paham dengan cara bermain dan memanipulasi objek di sekitarnya serta bergerak aktif. Jadi media adalah alat yang digunakan untuk menyampaikan materi dan dapat merangsang peserta didik untuk bermain dan belajar.

Menurut Lindawati (dalam Putu : 2015), engklek merupakan permainan yang sudah diturun temurunkan dari nenek moyang permainan ini 
dilaksanakan dengan cara berjalan atau melompat dengan menggunakan satu kaki. Menurut Wardani (2010) Permainan tradisional engklek juga disebut dengan Somdah. Somdah merupakan permainan yang dimainkan oleh anak dengan menggunakan media gambar persegi empat yang digambarkan di lantai atau tanah.

Dari pemaparan pendapat tersebut dapat disimpulkan, bahwa permainan tradisional adalah permainan yang diturun-temurunkan oleh nenek moyang dan dimainkan oleh anak-anak dengan cara berjalan atau melompat di tempat yang datar dengan menggunakan satu kaki. Permainan tersebut mengandung unsur kebudayaan. Permaianan engklek merupakan permainan yang popular dimainkan oleh anak usia dini, namun pada kenyataannya, pendidik sebagai fasilitator dalam pembelajaran memiliki kendala untuk memilih media yang tepat untuk anak. Kegiatan mengenalkan geometri pada anak, masih menggunakan media yang monoton sehingga kurang menarik perhatian anak. Akibatnya, anak menjadi mudah bosan dan tujuan utama dari pembelajaran yang diharapkan tidak dapat tersampaikan dengan baik. Padahal, dengan media, anak-anak mendapatkan kepuasan kinestetik karena hal tersebut sangat penting bagi perkembangan motorik kasarnya (Sulyandari, 2019).

Sebagian besar pendidik menggunakan media BKA (Buku Kraesi Anak). Peneliti merasa kurang puas terhadap materi mengenal geometri yang akan disajikan pada permainan tradisional engklek. Padahal menurut Montesori (2013) tujuan pembelajaran di TK adalah mengembangkan daya pikir anak sehingga penilaian dapat dilakukan saat anak-anak beraktivitas.Berdasarkan uraian masalah tersebut perlu adanya uji kelayakan ahli materi pada pengembangan media permainan tradisional engklek dikonsep geometri.

\section{B. Metode}

Penelitian ini dalam melaksanakan pengembangan dengan menggunakan model Thiagarajan 4-D yang meliputi (Define, Design, Develop, Dissemnate) atau diadaptasikan dengan istilah Pendefinisian, Perancangan, Pengembangan, Penyebaran. Peneliti melakukan tahap ini sampai Develop (Pengembangan), karena kondisi pandemic COVID-19 saat ini. Pada tahap Define, Peneliti melakukan pengkajian mengenai materi. Tahap Design Peneliti merancang materi yang akan disajikan. Pada Tahap Develop peneliti melakukan Uji kelayakan materi kepada ahli materi, yang terdiri dari dua orang ahli materi yang merupakan salah satu dosen dari UNIVERSITAS PGRI RONGGOLAWE TUBAN. Dalam pengumpulan data kita melakukan uji validasi 
kepada ahli materi. Instrument yang digunakan peneliti adalah lembar penilaian validasi ahli materi yang dilakukan oleh dua orang validator, yang terdiri dari 3 indikator yang berjumlah 13 butir soal angket. Lembar penilaian dikembangkan dengan menggunakan skala likert. Sampel ini kita hanya mengambil dari uji validasi dari dua ahli materi.

\section{Hasil dan Pembahasan}

Untuk mengetahui kelayakan materi, peneliti melakukan uji validasi terhadap dua orang ahli materi. Beliau merupakan salah satu dosen Prodi PG PAUD UNIROW, beliau juga merupakan seorang magister dalam bidangnya. Dibawah ini hasil dari uji validasi terhadap ahli materi:

Tabel 1. Hasil Validasi Ahli Materi

\begin{tabular}{|c|c|c|c|c|c|c|c|}
\hline \multirow{2}{*}{$\begin{array}{l}\text { Indikator } \\
\text { penilaian }\end{array}$} & \multirow[t]{2}{*}{ Materi } & \multicolumn{2}{|c|}{ Skor } & \multirow[t]{2}{*}{$\mathbf{R A}$} & \multirow[t]{2}{*}{$\mathbf{R I}$} & \multirow[t]{2}{*}{ RT } & \multirow[t]{2}{*}{ Keterangan } \\
\hline & & 1 & 2 & & & & \\
\hline \multirow[t]{3}{*}{$\begin{array}{l}\text { Kesesuaian } \\
\text { dengan } \\
\text { Kompetensi } \\
\text { Dasar (KD) }\end{array}$} & $\begin{array}{l}\text { 1. Kesesuaian Materi } \\
\text { dengan KD }\end{array}$ & 4 & 4 & 4 & \multirow[t]{3}{*}{4} & \multirow{4}{*}{3,8} & \multirow{4}{*}{ Valid } \\
\hline & $\begin{array}{l}\text { 2. Kesesuaian } \\
\text { Indikator dengan } \\
\text { KD }\end{array}$ & 4 & 4 & 4 & & & \\
\hline & & & & & & & \\
\hline $\begin{array}{c}\text { Aspek } \\
\text { Pembelajaran }\end{array}$ & 3. Petunjuk belajar & 4 & 3 & 3,5 & & & \\
\hline
\end{tabular}


Nurul Istiqomah, Ifa Aristia Sandra E.

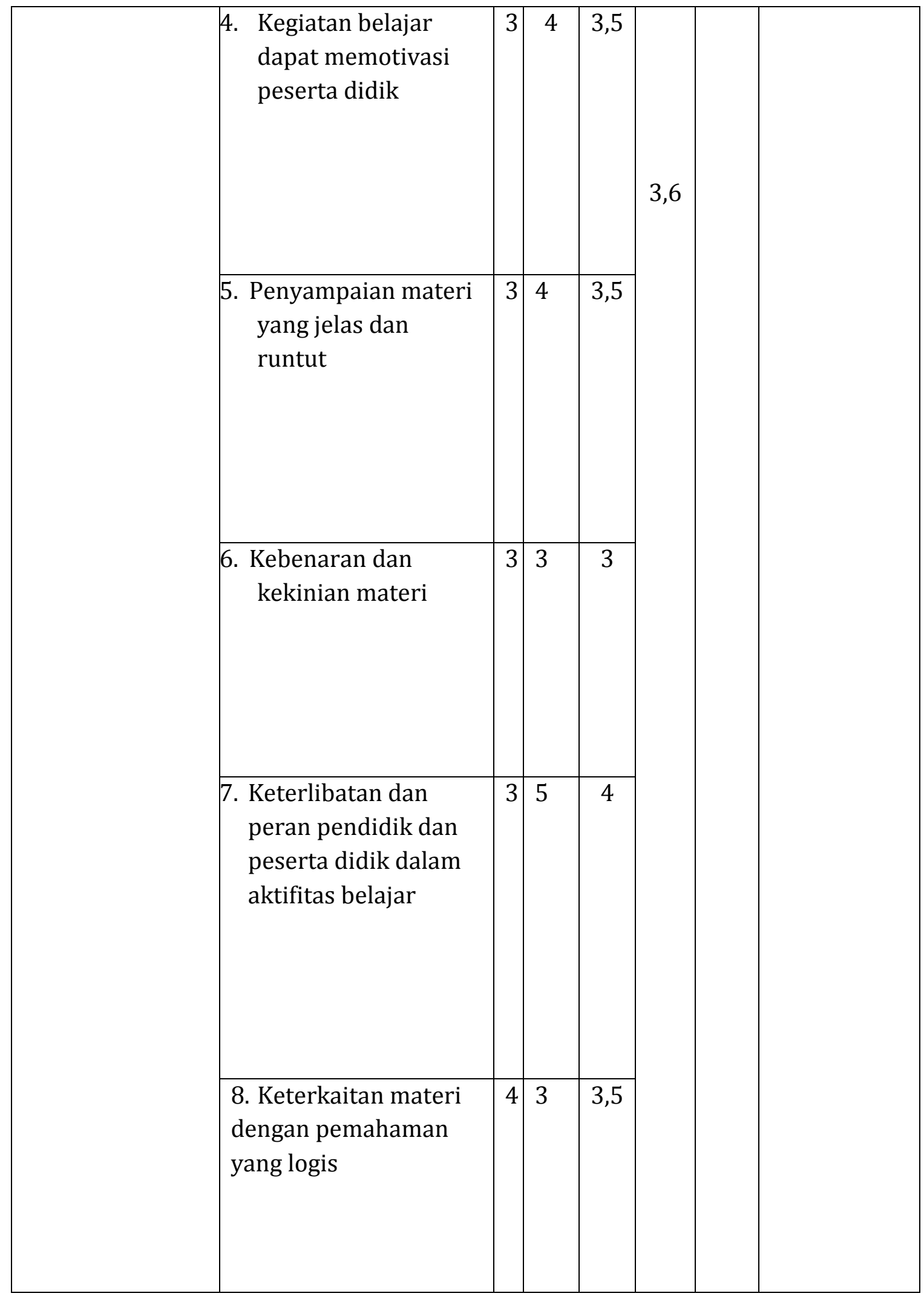

Thufuli: Volume 2 Nomor 2, Tahun 2020 
Nurul Istiqomah, Ifa Aristia Sandra E.

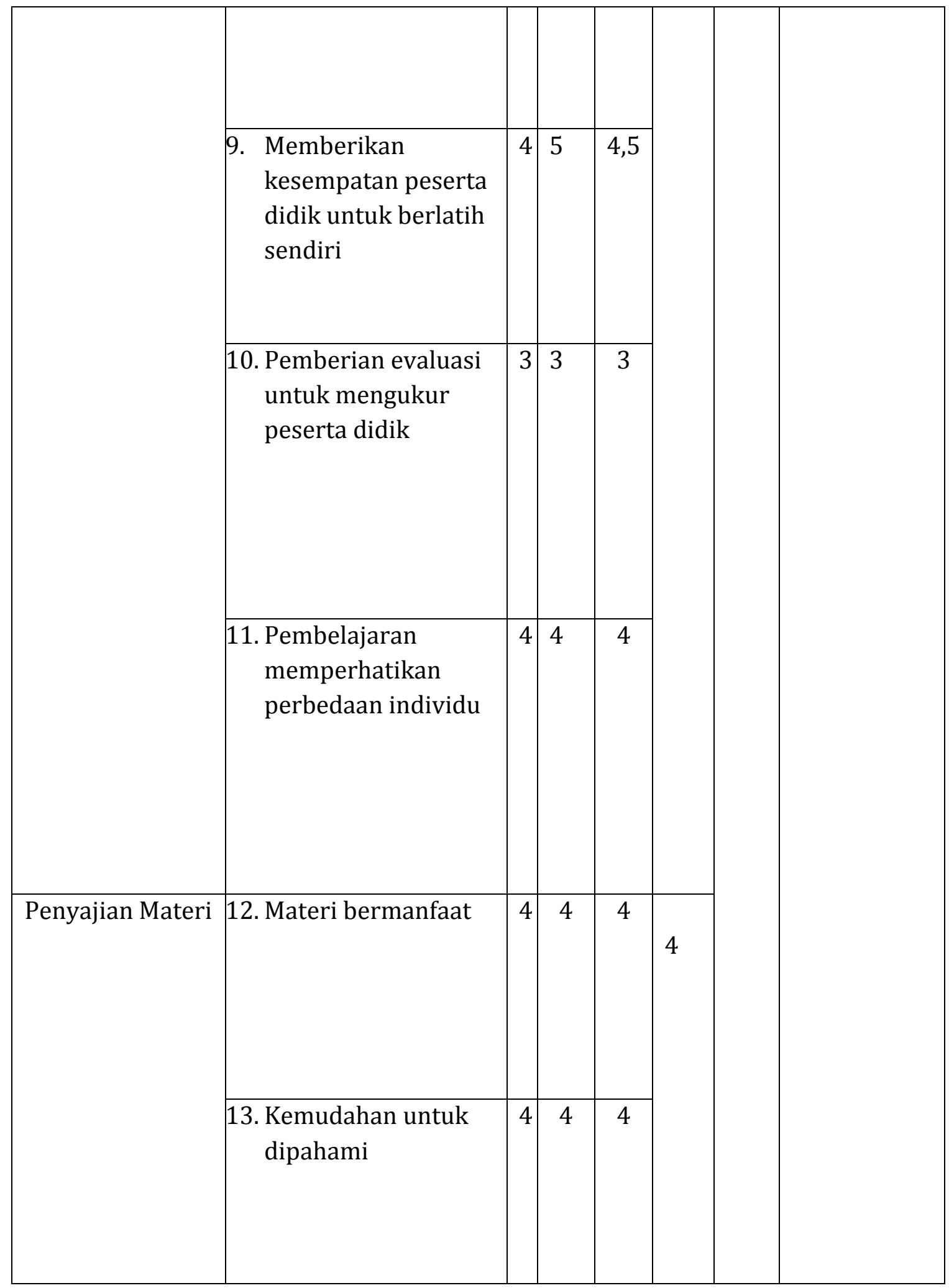

Thufuli: Volume 2 Nomor 2, Tahun 2020 
Nurul Istiqomah, Ifa Aristia Sandra E.

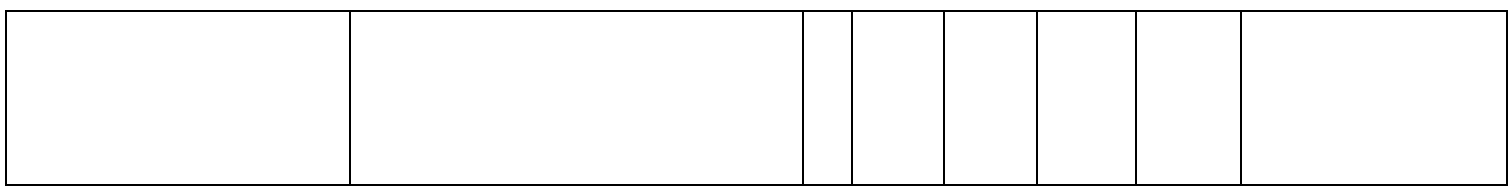

Keterangan:

RA : Rata-rata Aspek

RI : Rata-rata Indikator

RT : Rata-rata Total

Pada indikator kesesuaian dengan kompetensi dasar (KD)ini ada 2 materi. Dalam 2 materi yang ada ini maksutnya adalah antara materi dan kompetensi dasar dengan media yang dibuat peneliti sudah sesuai, dan Kompetensi Dasar (KD) yang digunakan adalah 3.6 dan 4.6, skor dari validator 1 sebanyak 8 dan validator 2 sebanyak 8, jadi rata-rata indikator sebanyak 4 .

Pada indikator aspek pembelajaran, disini ada 9 materi yang meliputi petunjuk belajar, kegiatan belajar dapat memotivasi peserta didik, penyampaian materi yang jelas dan runtut, kebenaran materi, keaktifan peserta didik, keterkaitan materi dengan pemahaman yang logis, memberikan kesempatan peserta didik untuk berlatih sendiri, pemberian evaluasi untuk mengukur peerta didik, pembelajaran memperhatikan perbedaan individu. Dari 9 materi tersebut itu dilakukan harus sesuai dengan media yang ada. Dalam hal ini kegiatan yang dilakukan peserta ddidik agar sesuai dengan materi adalah ketika anak menginjak di media dengan bentuk geometri anak sambil mengucapkan bentuk geometri yang diinjaknya. Sehingga anak akan mengetahui bentuk geometri. Untuk skor yang diperoleh dari validator 1 sebanyak 31 dan validator 2 sebanyak 34, jadi rata-rata indikator ada 3.6.

Untuk indikator penyajian materi ada 2 materi yang disampaikan. Dalam hal tersebut materi yang disampaikan harus ada manfaatnya buat peserta didik dan memudahkan peserta didik untuk memahaminya. Jadi dengan memakai media yang dibuat oleh peneliti peserta didik bisa lebih mudah untuk mengenal geometri. Skor yang didapat dari masing-masing validator ada 4. Dengan nilai rata-rata indikator 4 .

Berdasarkan tabel 1 dapat dilihat hasil dari validasi ahli materi rata-rata indikator Kesesuaian dengan Kompetensi Dasar (KD) adalah 4 yang berati media cukup valid untuk digunakan. Untuk indikator Aspek Pembelajaran rata-ratanya 
Nurul Istiqomah, Ifa Aristia Sandra E.

adalah 3,6 yang berati aspek pembelajaran cukup valid. Untuk indikator Penyajian Materi rata-ratanya adalah 4 yang berarti penyajian materi valid Sedangkan untuk rata-rata keseluruhan adalah 3,8 yang berati materi dan media valid untuk digunakan setelah melalui tahapan validasi, peneliti mendapat saran dari validator sebagai bahan revisi produk. Berikut adalah rincian saran dari para validator:

1. Validator 1: Untuk mengenalkan bentuk geometri. Lebih baik anak melompat dengan menggunakan satu kaki atau dua kaki sambal menyebutkan bentuk geometri yang diinjak

2. Validator 1 : Agar anak-anak tertarik dengan media tersebut. Lebih baik Setelah anak faham, guru membuat game media

Dari data yang diperoleh dari tabel 1 menunjukkan rata-rata total dari indikator Kesesuaian dengan Kompetensi Dasar (KD) adalah 4 dengan kriteria kelayakan 80\%. Untuk indikator Aspek Pembelajaran adalah 3,6 dengan kriteria kelayakan 72\%. indikator Penyajian Materi adalah 4 dengan kelayakan 80\%.

Data hasil validasi dari ahli materi dapat dilihat di grafik di bawah ini:

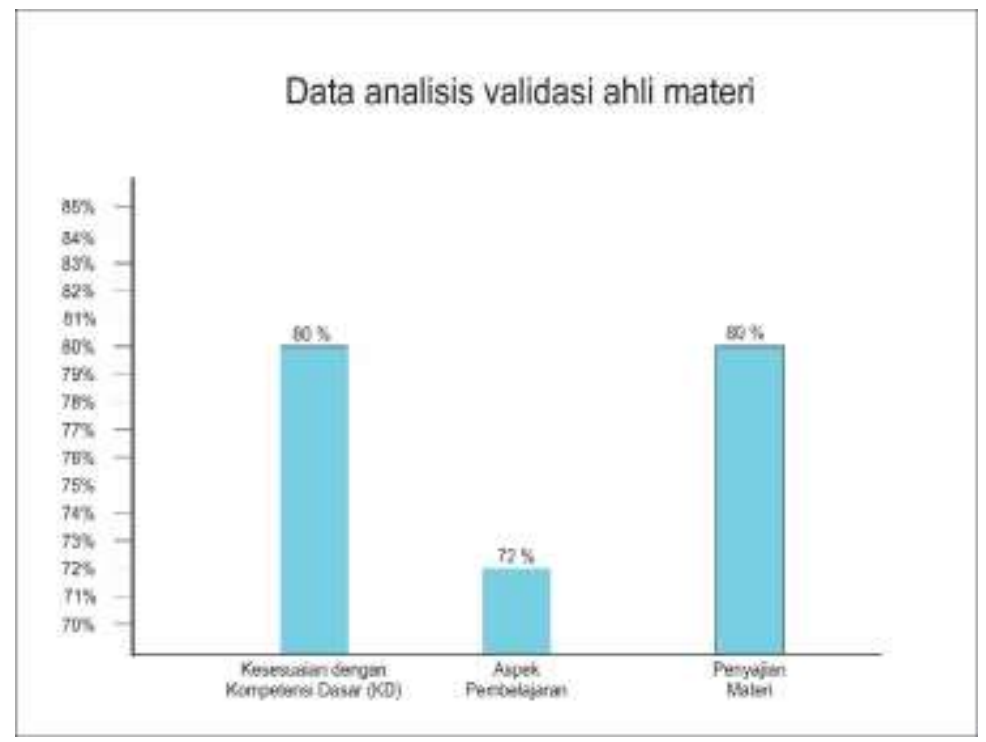

Gambar . 1 Data analisis validasi ahli materi

Dari data tersebut didapatkan rata-rata prosentase kelayakan media secara keseluruhan adalah 77,3\% dengan kriteria kelayakan "Layak". Hal ini berati mediayang dikembangkan oleh peneliti layak untuk digunakan dalam pembelajaran mengenal geometri. Menurut Cheeseman (2008) alat peraga akan memperkuat daya ingat anak. 


\section{Simpulan}

Setelah melakukan uji validasi terhadap ahli materi untuk mengetahui kelayakan materi pada media permainan tradisional engklek geometri. Kemudian peneliti memperoleh hasil yaitu materi yang diujikan peneliti adalah "layak" untuk digunakan atau di sajikan, sehingga pembelajaran yang awalnya monoton menggunakan lembar kerja, kini dapat dilaksanakan menggunakan media pembelajaran engklek untuk mengenal geometri, karena media sangat membantu pemahaman anak-anak untuk belajar.

\section{Daftar Pustaka}

Ana, D. P, Fajryana, S. F \& Mayangsari, D. (2018). Jurnal PG-PAUD Trunojoyo : Jurnal Pendidikan dan Pembelajaran Anak Usia Dini, 5(2), 86-100

Anderson Jona K. (2010). The Importance of Play in Early Childhood Development. Bozeman: Extension, http://store.msuextension.org/publications/HomeHealthandFamily/MT201003HR.pdf

Beaty, J.J. Skills for Preschool Teachers. New Jersey: Prentice-Hall.

Bustang. (2011). Four -D Model ( Model Pengembangan Perangkat pembelajaran Dari Thiagarajan, Dkk. Htttps://bustangbuhari.wordpress.com/2011/08/25/f our-d-model-model-pengembangan-perangkat-pembelajran-dari-thiagarajan$\mathrm{dkk} /$

Ginanjar, A. (2010). Pengembangan Media Pembelajaran Modul Interaktif Mata

Mentari, R. D, Riswandi \& Surahman. M. tanpa tahun. PengenalangGeometri Anak Usia Dini Melalui Media Manipulatif.

Montesori, Maria. Tanpa Tahun. Metode Montesori. Terjemah Gutex, Gerald Lee. 2013. Yogyakarta: Pustaka Pelajar.

National Council for Teachers of Mathematic. 2000. Principles and Standarda for School National Council of Teachers of Mathematics.www.nctm.org Leong, Deborah J. and Elena Bodrova. 2012. Assessing and Scaffolding MakeBelieve Play. National Association for the Education of Young Children Sulyandari, Ari. (2019). Pengembangan Pembelajaran Mengenal Bilangan melalui Tangga Manik-Manik Montessori di Kelas A TK Anggrek Karangploso Malang http://journal.iaialhikmahtuban.ac.id/index.php/ijecie/article /view/78 3(2)

Sulyandari, Ari. (2017). Representasi Simbol Matematika dalam Proses bermain pada Anak TK. Jurnal Pendidikan: Teori, Penelitian, dan Pengembangan 1 (11) 
Nurul Istiqomah, Ifa Aristia Sandra E.

Sulyandari, Ari. 2019. Pengembangan Sirkuit Bongkar Pasang untuk Aktivitas Fisik Motorik Kasar di Lembaga Prasekolah dengan Lahan Minimalis. SELING:

Jurnal Program Studi PGRA 6 (2)

Trisna, K. M, Putu, L. P. M \& Magta, M. !2016) PenerapanpPermainan Tradisional Engklek Untuk Meningkatkan Kemampuan Motorik Kasar Kelompok B Di Paud Widhya Laksmi. e-Journal Pendidikan Anak Usia Dini Universitas Pendidikan Ganesha Jurusan Pendidikan Guru Pendidikan Anak Usia Dini 4(2)

Wolfinger, Donna M. (1994). Science and Mathematics in Early-Childhood Education. America: Harper Collins College Publisher 